\title{
I3-[CH $\left.\mathrm{CH}_{2} \mathrm{CO}-\mathrm{Cys}-(\mathrm{Bzl})-\mathrm{OBzl}\right]-$ Berberine: Exploring The Correlation Of Anti-Tumor Efficacy With ROS And Apoptosis Protein
}

This article was published in the following Dove Press journal: OncoTargets and Therapy

\author{
Guanyu $\mathrm{Li}^{1,2}$ \\ Yi Ren ${ }^{1,2}$ \\ Xiaoyi Zhang ${ }^{1,2}$ \\ Shurui Zhao ${ }^{1,2}$ \\ Yaonan Wang $\mathbb{D}^{1,2}$ \\ Jianhui $\left.\mathrm{Wu}_{(\mathbb{D}}\right)^{1,2}$ \\ Shiqi Peng $\mathbb{D}^{1,2}$ \\ Ming Zhaol-3 \\ 'Beijing Area Major Laboratory of \\ Peptide and Small Molecular Drugs, \\ Department of Medicinal Chemistry, \\ School of Pharmaceutical Sciences, \\ Capital Medical University, Beijing \\ 100069, People's Republic of China; \\ ${ }^{2}$ Engineering Research Center of \\ Endogenous Prophylactic of Ministry of \\ Education of China, School of \\ Pharmaceutical Sciences, Capital Medical \\ University, Beijing 100069, People's \\ Republic of China; ${ }^{3}$ Beijing Laboratory of \\ Biomedical Materials and Key Laboratory \\ of Biomedical Materials of Natural \\ Macromolecules, Beijing University Of \\ Chemical Technology, Beijing 100026, \\ People's Republic of China
}

Background: The discovery of novel derivative of berberine (BBR) having higher antitumor activity in vivo is of clinical importance. In this profile, $13-\left[\mathrm{CH}_{2} \mathrm{CO}-\mathrm{Cys}-(\mathrm{Bzl})-\mathrm{OBzl}\right]-$ berberine (13-Cys-BBR) was prepared for related assays.

Purpose: The object of preparation and evaluation is to show the advantages of 13-CysBBR over BBR in both in vitro and in vivo anti-tumor actions, furthermore to correlate the proliferation of cancer cells with ROS formation and anti-apoptosis protein (XIAP) expression inside cancer cells.

Methods: Transwell chamber was used to simulate the intestinal and cell wall for bioavailability evaluation; MTT assay was used to evaluate the in vitro anti-proliferation activity; fluorescein isothiocyanate content was used to represent ROS level in HCT-8 cells; Western blot assay was used to quantify the expression of XIAP, caspase-3, and poly ADP-ribose polymerase in HCT- 8 cells; and S180 mouse model was used to evaluate the in vivo antitumor activity.

Results: In vitro the $\mathrm{IC}_{50}$ values $(\sim 15-40 \mu \mathrm{M})$ of $13-\mathrm{Cys}-\mathrm{BBR}$ against the proliferation of eight cancer cell lines were significantly lower than those of BBR $(\sim 25-140 \mu \mathrm{M})$; the content of ROS formed inside HCT-8 cells treated by 13-Cys-BBR was $\sim 3.44$-folds higher than that inside HCT- 8 cells treated by BBR; the expression of XIAP in HCT- 8 cells treated by 13-Cys -BBR was $\sim 1.21$-folds lower than that in HCT- 8 cells treated by BBR; the tumor weight of S180 mice orally treated by $2 \mu \mathrm{mol} / \mathrm{kg} / \mathrm{day}$ of 13 -Cys-BBR $(\sim 1.5 \mathrm{~g})$ was significantly lower than that of S180 mice orally treated by $2 \mu \mathrm{mol} / \mathrm{kg} /$ day of BBR $(\sim 2.5 \mathrm{~g})$; and the active pocket of XIAP was more suitable for 13-Cys-BBR than for BBR.

Conclusion: The anti-tumor action correlates with ROS and apoptosis protein, which suggests 13-Cys-BBR is a promising candidate for preclinical study.

Keywords: berberine, 13-position modification, anti-tumor, ROS, XIAP

\section{Introduction}

Berberine (BBR) is a typical representative of bioactive components extracted from traditional herbs. ${ }^{1}$ The in vitro and in vivo pharmacological actions of BBR have been well documented. In vitro BBR attenuated sodium palmitate-induced lipid accumulation, ${ }^{2}$ inhibited tumor cell proliferation, ${ }^{3}$ decreased the secretion of IL- $2,{ }^{4}$ weakened CYP1-catalyzed region selective hydroxylation of estradiol, ${ }^{5}$ induced neuronal differentiation, ${ }^{6}$ stopped glutamate-induced neurodegeneration, ${ }^{7}$ broke double-strand of DNA, ${ }^{8}$ mediated the secretion of glucagon-like peptide $1,{ }^{9}$ decreased HaCaT apoptosis, ${ }^{10}$ inhibited human cytomegalovirus replication, ${ }^{11}$ induced cell
Correspondence: Shiqi Peng; Ming Zhao Department of Medicinal Chemistry, School of Pharmaceutical Sciences, Capital Medical University, No. 10, Youanmenwaixitoutiao, Fengtai District, Beijing 100069, People's Republic of China Tel +86 I0839II528; +86 I0839II 535 Fax +86 I0839II528; +86 I0839II533 Email sqpeng@bjmu.edu.cn; mingzhao@bjmu.edu.cn 
cycle arrest, ${ }^{12}$ and suppressed lipopolysaccharide-induced inflammation. ${ }^{13}$ In vivo BBR slowed the growth and inhibited the metastasis of endometrial cancer, ${ }^{14}$ slowed the growth and inhibited lung metastases of hepatocellular carcinoma, ${ }^{15}$ cured chronic ulcerative colitis, ${ }^{16}$ alleviated type 2 diabetes, ${ }^{17}$ and ameliorated musculoskeletal disorders (osteoporosis, osteoarthritis, and rheumatoid). ${ }^{18}$

On the other hand, the poor bioavailability of BBR restricted its clinical use. To overcome this shortcoming, some efforts were made. Among them, the representative strategies were the complexation of BBR and $\gamma$-cyclodextrin, ${ }^{19}$ the conjugation of BBR and baicalein, ${ }^{20}$ the combination of BBR with 5-aminosalicylic acid, ${ }^{21}$ and the formation of the dendrimer-BBR supramolecule. ${ }^{22}$ However, the strategy of structural modification remains rare. In this context, here $\mathrm{CH}_{2} \mathrm{CO}-\mathrm{Cys}(\mathrm{Bzl})-\mathrm{OBzl}$ was selected to modify the 13-position of $\mathrm{BBR}$ and form 13- $\left[\mathrm{CH}_{2} \mathrm{CO}-\mathrm{Cys}(\mathrm{Bzl})-\mathrm{OBzl}\right]$-berberine (13-Cys-BBR). For this purpose transwell chamber was used to simulate intestinal wall or cell wall. The efficacy of 13-Cys-BBR and BBR crossing the membrane of the transwell was represented by UV absorption. The results showed that the efficacy of 13-Cys-BBR crossing intestinal wall or cell wall was significantly higher than that of BBR. These led 13-Cys -BBR to a series of assays.

\section{Materials And Methods}

\section{General}

All commercially available chemicals were from Sigma Chemical Co. and purified when necessary. The purity of all compounds was identified with TLC (Qingdao silica gel F254, $0.25 \mathrm{~mm}$ layer thickness) or HPLC (Waters, C18 column, $4.6 \times 150 \mathrm{~mm}$ ). Bruker Avance II-300 or Bruker Avance III-800 spectrometer was used to record the ${ }^{1} \mathrm{H}$ NMR (300 or $800 \mathrm{MHz}$ ) and ${ }^{13} \mathrm{C}$ NMR (75or 200 $\mathrm{MHz})$ spectra, while DMSO- $d_{6}$ was the solvent and tetramethylsilane was the internal standard. ZQ 2000 mass spectrometer (Waters, US) or Fourier transform ion cyclotron resonance (FT-ICR, 9.4T solariX, Bruker, US) with dual ion source of ESI/matrix-assisted laser desorption ionization ESI/MS was used for mass analyses.

HCT-116, LS174T, SW620, SGC7901, Eca109, MKN28, HCT-8, and S180 cells were purchased from key GENBioTECH (Nanjing China). Male ICR mice (22 \pm 2 g) were purchased commercially from Laboratory Animal Center of Capital Medical University. In vitro and in vivo assays were examined by the Ethics Committee of Capital
Medical University. The committee approved that the assays can use the mentioned cells and mice can be used for the assays, and assured that the welfare of mice met the requirements of Animal Welfare Act and NIH Guide for Care and Use of Laboratory Animals.

Biological data were statistically analyzed with ANOVA, and the $P$-value less than 0.05 was considered statistically significant.

\section{Synthesis}

\section{3-Cys-BBR}

The synthetic route of 13-Cys-BBR is shown in Figure 1. The route consists of 4-step reactions. The total yield of the 4 -step reactions was $12 \%$. The synthetic strategy is capable of satisfying the pre-clinical investigations.

\section{Preparing 7,8-Dihydro-8- $\mathrm{CH}_{2} \mathrm{COCH}_{3}$-Berberine}

At room temperature, $10 \mathrm{~g}(26.9 \mathrm{mmol})$ of berberine hydrochloride (purchased from Sigma-Aldrich) was dissolved in $50 \mathrm{~mL}$ of aqueous $\mathrm{NaOH}(5 \mathrm{M})$, into this sloution $10 \mathrm{~mL}$ of acetone was dropped gradually within $1 \mathrm{hr}$, and this mixture was stirred for another $3 \mathrm{hrs}$. At $0^{\circ} \mathrm{C}$ the $\mathrm{pH}$ of the reaction mixture was adjusted to 7 by adding hydrochloric acid $(10 \mathrm{M})$ dropwise. The reaction mixture was filtered, the filtrate was extracted with methanol $(80 \%)$, and $9.45 \mathrm{~g}(82 \%)$ of the title compound were obtained. $^{27}$

\section{Preparing $13-\mathrm{CH}_{2} \mathrm{CO}_{2} \mathrm{C}_{2} \mathrm{H}_{5}$-Berberine Hydrobromide}

A solution of $5 \mathrm{~g}$ (12.7 $\mathrm{mmol})$ of $1,1.6 \mathrm{~mL}$ of ethyl bromoacetate, $170 \mathrm{mg}$ of $\mathrm{NaI}$, and $150 \mathrm{~mL}$ of acetonitrile was stirred at $80^{\circ} \mathrm{C}$ for $6 \mathrm{hrs}$, and then cooled down to room temperature. The reaction mixture was filtered, the filtrate was evaporated in vacuum, and the residue was purified on silica gel column $\left(\mathrm{CH}_{2} \mathrm{Cl}_{2} / \mathrm{MeOH}, 10 / 1\right)$ to give $2.82 \mathrm{~g}(49 \%)$ of the title compound. $\mathrm{ESI}(+) / \mathrm{MS}(\mathrm{m} / \mathrm{e}): 422 \quad[\mathrm{M}-\mathrm{Br}]^{+} \cdot{ }^{1} \mathrm{H} \quad \mathrm{NMR}$ $\left(\mathrm{DMSO}-d_{6}, 300 \mathrm{MHz}\right) \delta / \mathrm{ppm}=10.021(\mathrm{~s}, 1 \mathrm{H}), 8.254(\mathrm{~d}$, $J=9.6 \mathrm{~Hz}, 1 \mathrm{H}), 8.015$ (d, $J=9.6 \mathrm{~Hz}, 1 \mathrm{H}), 7.187$ (s, $1 \mathrm{H})$, $7.097(\mathrm{~s}, 1 \mathrm{H}), 6.696(\mathrm{~s}, 2 \mathrm{H}), 4.436(\mathrm{~s}, 2 \mathrm{H}), 4.238\left(\mathrm{dd}, J_{1}=\right.$ $\left.7.2 \mathrm{~Hz}, J_{2}=13.8 \mathrm{~Hz}, 2 \mathrm{H}\right), 4.116(\mathrm{~s}, 3 \mathrm{H}), 4.093(\mathrm{~s}, 3 \mathrm{H})$, $3.120(\mathrm{t}, J=7.2 \mathrm{~Hz}, 2 \mathrm{H}), 1.266(\mathrm{t}, J=13.8 \mathrm{~Hz}, 3 \mathrm{H}){ }^{27}$

Preparing $13-\mathrm{CH}_{2} \mathrm{CO}_{2} \mathrm{H}$-Berberine Hydrochloride

At room temperature, a solution of $2 \mathrm{~g}$ (4.4 mmol) of 2 , $15 \mathrm{~mL}$ of methanol (50\%), and $15 \mathrm{~mL}$ of water was stirred, during $10 \mathrm{hrs}$ into this solution aqueous $\mathrm{NaOH}$ (2 M) was added dropwise to keep $\mathrm{pH} \mathrm{13,} \mathrm{and} \mathrm{TLC}$ $\left(\mathrm{CH}_{2} \mathrm{Cl}_{2} / \mathrm{MeOH}, \quad 10 / 1\right)$ indicated the complete 


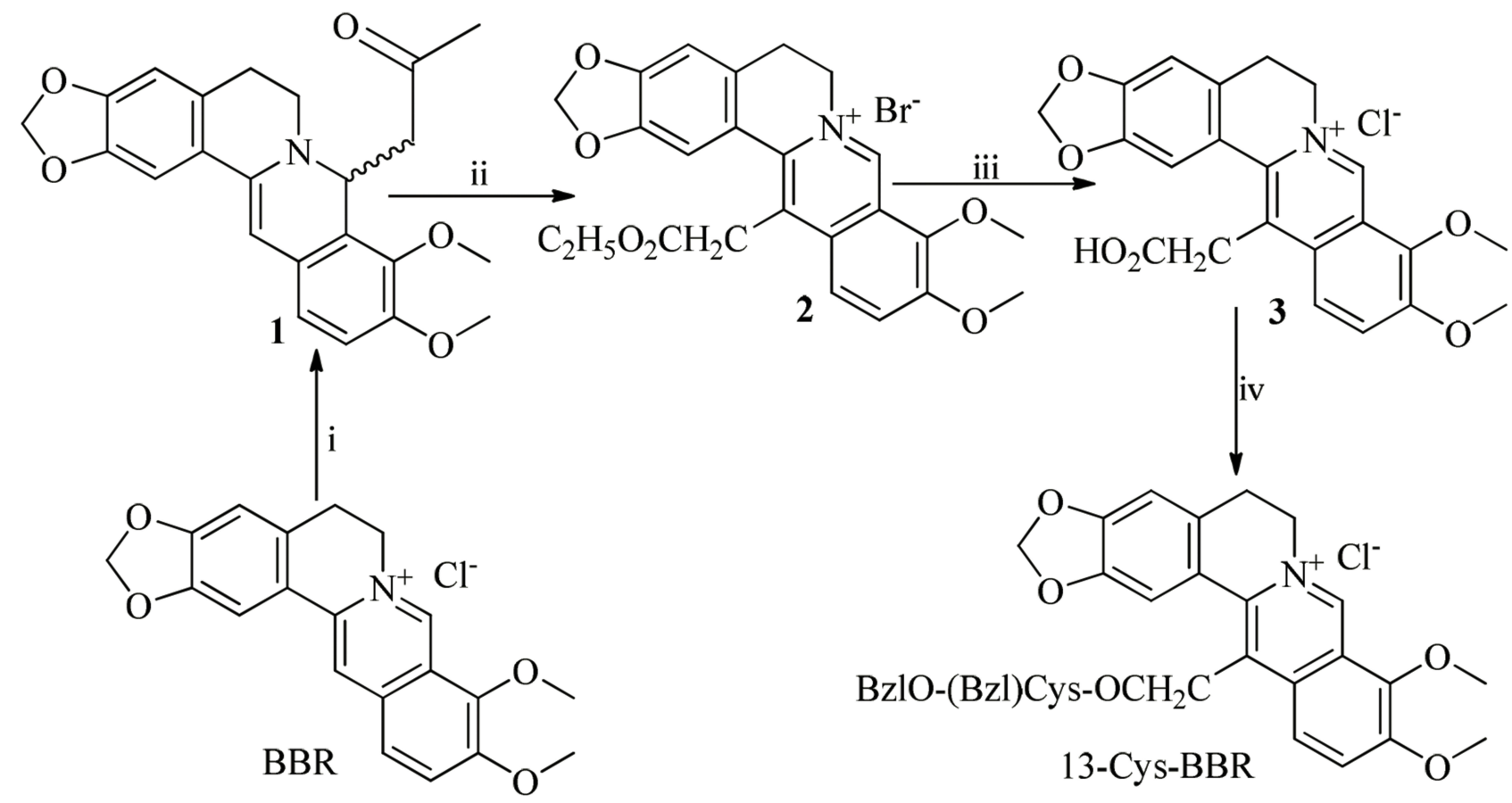

Figure I Reagents and conditions: (i) aqueous $\mathrm{NaOH}\left(5 \mathrm{M}\right.$ ), acetone, 3 hrs and room temperature; (ii) ethyl bromoacetate, $\mathrm{Nal}, \mathrm{CH}_{3} \mathrm{CN}, 6$ hrs and $80^{\circ} \mathrm{C}$; (iii) $\mathrm{NaOH}$ in methanol (2 M), $\mathrm{HCl}, 10 \mathrm{hrs,} \mathrm{room} \mathrm{temperature;} \mathrm{(iv)} \mathrm{HBTu,} \mathrm{Cys(Bzl)-OBzl,} \mathrm{N-methylmorpholine,} 48$ hrs and room temperature.

Abbreviations: BBR, berberine; I3-Cys-BBR, I3-[CH $\left.\mathrm{CH}_{2} \mathrm{CO}-\mathrm{Cys}(\mathrm{Bz} \mid)-\mathrm{OBz} \mid\right]-$ berberine; HBTu, 2-(IH-Benzotriazole-I-yl)-I, I,3,3-tetramethylaminium hexafluorophosphate.

disappearance of 2 . The reaction mixture was evaporated in vacuum, the $\mathrm{pH}$ of the residue was adjusted to 5 by dilute hydrochloric acid to give $1.73 \mathrm{~g}(94 \%)$ of the title compound. $\quad \mathrm{ESI}(+) / \mathrm{MS}(\mathrm{m} / \mathrm{e}): \quad 394[\mathrm{M}-\mathrm{Cl}]^{+} \cdot{ }^{1} \mathrm{H} \quad \mathrm{NMR}$ $\left(\right.$ DMSO- $\left.d_{6}, 300 \mathrm{MHz}\right) \delta / \mathrm{ppm}=10.040(\mathrm{~d}, J=9 \mathrm{~Hz}, 1$ $\mathrm{H}), 8.254\left(\mathrm{dd}, J_{1}=9 \mathrm{~Hz}, J_{2}=9.6 \mathrm{~Hz}, 1 \mathrm{H}\right), 8.014\left(\mathrm{dd}, J_{1}=\right.$ $\left.9 \mathrm{~Hz}, J_{2}=15 \mathrm{~Hz}, 1 \mathrm{H}\right), 7.195(\mathrm{~d}, J=15 \mathrm{~Hz}, 2 \mathrm{H}), 6.192$ (s, $2 \mathrm{H}), 4.817(\mathrm{~s}, 2 \mathrm{H}), 4.483(\mathrm{~s}, 1 \mathrm{H}), 4.357(\mathrm{~s}, 1 \mathrm{H}), 4.114$ $(\mathrm{s}, 3 \mathrm{H}), 4.088(\mathrm{~s}, 3 \mathrm{H}), 3.112(\mathrm{~s}, 2 \mathrm{H}){ }^{27}$

\section{Preparing 13-Cys-BBR}

At room temperature, a solution of $430 \mathrm{mg}(1 \mathrm{mmol})$ of 3 , $380 \mathrm{mg}(1 \mathrm{mmol})$ of HBTu, $340 \mathrm{mg}(1 \mathrm{mmol})$ of L-Cys(Bzl)-OBzl, $40 \mathrm{~mL}$ of tetrahydrofuran, and $5 \mathrm{~mL}$ of N-methylmethanesulfonamide was stirred, adjusted to pH 7 with N-methylmorpholine and stirred for $48 \mathrm{hrs}$. Then, the reaction mixture was evaporated in vacuum and the residue was purified on silica gel column $\left(\mathrm{CH}_{2}\right.$ $\left.\mathrm{Cl}_{2} / \mathrm{MeOH}, 90 / 1\right)$ to give $231 \mathrm{mg}$ (32\%) of title compound. FT-ICR-MS (m/e): 677.2408 [M-Cl] $^{+}$(calculated value: 677.2320). ${ }^{1} \mathrm{H}$ NMR (DMSO- $d_{6}, 800 \mathrm{MHz}$ ): $\delta / \mathrm{ppm}=$ $9.971(\mathrm{~s}, 1 \mathrm{H}), 9.312(\mathrm{~d}, J=7.2 \mathrm{~Hz}, 1 \mathrm{H}), 7.974(\mathrm{~s}, 2 \mathrm{H})$, 7.599 (s, $1 \mathrm{H}), 7.408$ (s, $5 \mathrm{H}), 7.247$ (s, $5 \mathrm{H}), 7.172$ (s, $1 \mathrm{H}), 6.152(\mathrm{~s}, 2 \mathrm{H}), 5.189(\mathrm{~s}, 2 \mathrm{H}), 4.849(\mathrm{~m}, 1 \mathrm{H})$, $4.723(\mathrm{~m}, 1 \mathrm{H}), 4.303(\mathrm{~s}, 2 \mathrm{H}), 4.103$ (s, $3 \mathrm{H}), 4.018$ (s, $3 \mathrm{H}), 3.805$ (s, $2 \mathrm{H}), 3.106$ (m, $2 \mathrm{H}), 2.927$ (m, $3 \mathrm{H})$. ${ }^{13} \mathrm{C}$ NMR (DMSO-d $\mathrm{d}_{6}, 200 \mathrm{MHz}$ ), $\delta / \mathrm{ppm}=170.7,170.4$, $150.8,149.9,147.3,145.9,144.7,138.4,137.9,136.2$, $134.5,133.4,129.4,128.9,128.4,128.5,128.2,127.8$, $127.4,126.3,121.5,121.4,120.5,109.7,108.9,102.5$, 66.9, 65.4, 62.5, 57.5, 57.4, 52.3, 37.7, 35.6, 32.6, 27.7. HPLC purity: $99.3 \%$.

\section{Bioassays}

\section{In Vitro Anti-Proliferation Assay} HCT-116, LS174T, SW620, SGC7901, Eca109, MKN28, HCT-8, and S180 cells in RPMI 1640 medium or DMEM medium supplemented with $10 \%$ FBS, penicillin $(100 \mathrm{U} / \mathrm{mL})$, and streptomycin $(100 \mu \mathrm{g} / \mathrm{mL})$ were maintained in a humidified atmosphere of $5 \% \mathrm{CO}_{2}$ at $37^{\circ} \mathrm{C}$. The medium was renewed every 2 days and the proliferation of these cells was determined by MTT method. For this purpose, the cells in logarithmic growth phase were digested with $0.25 \%$ trypsin, added to RPMI 1640 medium or DMEM medium supplemented with $10 \%$ FBS, plated into 96-well plates (4000 cells per well), and incubated for $8 \mathrm{hrs}$. Then, the cells were treated with the medium (blank control) or Dox (positive control, final concentration: 50 $\mu \mathrm{M}$ ), BBR (positive control, final concentration: 100, 50, and $25 \mu \mathrm{M}$ ), or 13-Cys-BBR (final concentration: 100, 50, 
and $25 \mu \mathrm{M}$ ) for $48 \mathrm{hrs}, 25 \mu \mathrm{L}$ solution of MTT was added and the plates were incubated at $37^{\circ} \mathrm{C}$ for $4 \mathrm{hrs}$, and the supernatant was discarded, and then $150 \mu \mathrm{L}$ of DMSO was added to dissolve the formed formazan. The optical density (OD) value of the wells treated by medium or BBR or 13-Cys-BBR was read with Spectra Mas M3 microplate reader (BioTek, Winooski, VT, US) at $570 \mathrm{~nm}$.

\section{Time-Dependent Anti-Proliferation Assay Of HCT-8 Cells In Vitro}

HCT-8 cells were similarly incubated to the in vitro antiproliferation assay and treated by BBR $(50 \mu \mathrm{M})$ or 13-CysBBR $(50 \mu \mathrm{M})$ or doxorubicin (Dox, $50 \mu \mathrm{M})$ for $6,9,12,15$, 18,21 , and $24 \mathrm{hrs}$. Then, $25 \mu \mathrm{L}$ of solution of MTT was added and the plates were incubated at $37^{\circ} \mathrm{C}$ for $4 \mathrm{hrs}$, and the supernatant was discarded, and then $150 \mu \mathrm{L}$ of DMSO was added to dissolve the formed formazan. The OD value of the well treated by BBR or 13-Cys-BBR or Dox was read with Spectra Mas M3 microplate reader (BioTek, Winooski, VT, US) at $570 \mathrm{~nm}$.

\section{Testing ROS}

HCT-8 cells were cultured with RPMI 1640 medium containing $10 \% \mathrm{FBS}$, penicillin $(100 \mathrm{U} / \mathrm{mL})$, and streptomycin $(100 \mu \mathrm{g} / \mathrm{mL})$, and maintained at $37^{\circ} \mathrm{C}$ in humidified $\mathrm{CO}_{2}$ (5\%). The cells in logarithmic growth phase were digested with $0.25 \%$ trypsin, added to RPMI 1640 medium supplemented with $10 \%$ FBS, plated into 6 -well plates $\left(10^{6}\right.$ cells per well), and incubated for $8 \mathrm{hrs}$. The cells were treated with BBR $(50 \mu \mathrm{M})$ or $13-\mathrm{Cys}-\mathrm{BBR}(50 \mu \mathrm{M})$ for $6 \mathrm{hrs}$, into each well $200 \mu \mathrm{L}$ of DCFH-DA (KeyGENBioTECH, KGAF019, diluted 800 times with RPMI 1640 medium) were added, then digested with $0.25 \%$ trypsin and collected into a $1.5 \mathrm{~mL}-$ tube. After centrifugation (1000 $\mathrm{g}$ per min, $2.5 \mathrm{mins}$ ), the supernatant was removed, the residue was washed with PBS for 2 times, and then tested on flow cytometry and observed by fluorescence microscope (Beckman CytoFLEX). ${ }^{23}$

\section{In Vivo Anti-Tumor Assay}

S180 cells for this assay were provided by the tumorbearing mouse (purchased from Peking University Health Science Center) in an ascetic form. S180 cells were maintained in NS, the concentration was $1.5 \times 10^{7}$ viable cells/ $0.2 \mathrm{~mL}$ of NS, and were subcutaneously implanted into the skin of the right oxter of male ICR mice ( $22 \pm 2 \mathrm{~g})$. Four days after implantation, the mice were randomly divided into 4 groups (12 per group). The mice in positive control were intraperitoneally given Dox $(2 \mu \mathrm{mol} / \mathrm{kg} /$ day $)$ for 11 consecutive days, the mice in parent compound control were orally given BBR ( $2 \mu \mathrm{mol} / \mathrm{kg} /$ day) for 11 consecutive days, the mice in negative control were orally given $\mathrm{CMC}$ $\mathrm{Na}(10 \mathrm{~mL} / \mathrm{kg} /$ day $)$ for 11 consecutive days, and the mice in treatment group were orally given 13-Cys-BBR (2 $\mu \mathrm{mol} / \mathrm{kg} / \mathrm{day}$ ) for 11 consecutive days. Twenty-four hours after the last administration, all mice were anesthetized by ether to sample blood for the further assays and sacrificed to take the tumors for weighing.

\section{Liver And Kidney Toxicity Assay In Vivo}

The blood from S180 mice treated by 13-Cys-BBR or BBR was centrifuged to prepare the serum samples. The vitality of serum urea, lactate dehydrogenase (LDH), glutamic-pyruvic transaminase (ALT), uric acid (UA), and creatinine (CREA-S) was measured on biochemical analyzer by following the manuals.

\section{Testing Anti-Apoptosis Proteins}

HCT- 8 cells $\left(2 \times 10^{6} /\right.$ well $)$ were seeded in 6 -well plates and cultured for $8 \mathrm{hrs}$, and then the cells were treated with BBR $(25 \mu \mathrm{M})$ or 13-Cys-BBR $(25 \mu \mathrm{M})$ for $24 \mathrm{hrs}$. The cells were harvested, at $4^{\circ} \mathrm{C}$ washed twice with PBS, and then lysed with ice-cold radioimmunoprecipitation assay buffer (1\% NP-40 in $150 \mathrm{mM} \mathrm{NaCl}, 50 \mathrm{mM}$ Tris, and $2 \mathrm{mM}$ EDTA) for 30 mins. The anti-apoptosis protein (XIAP), caspase-3 (Cas-3), and poly ADP-ribose polymerase (PARP) from the lysate were run on a sodium dodecyl sulfate-polyvinylidene difluoride membrane. The membrane was blocked with BSA $(5 \%, \mathrm{~W} / \mathrm{V})$ for $2 \mathrm{hrs}$, washed thrice with tris-buffered saline Tween (TBST), and at $4^{\circ} \mathrm{C}$ incubated with primary antibodies XIAP or Cas-3 or PARP or actin (1:500) overnight. At room temperature, the membrane was washed, incubated for $1 \mathrm{hr}$ with IgG-horseradish peroxidase-conjugated secondary antibody, and washed thrice with TBST. Western blot chemiluminescence reagents of Western blot were added to visualize the bands of the proteins. ${ }^{9}$

\section{Results}

\section{3-Cys-BBR Effectively Crossing Transwell Membrane}

The ability of 13-Cys-BBR and BBR to cross the wall of intestinal or cancer cells was compared. For this purpose, transwell was used to simulate the wall of intestinal or cancer cells, and UV absorption was used to quantify 13-Cys-BBR and BBR occurring in the lower chamber of the transwell. Figure 2 shows that the concentration of BBR 

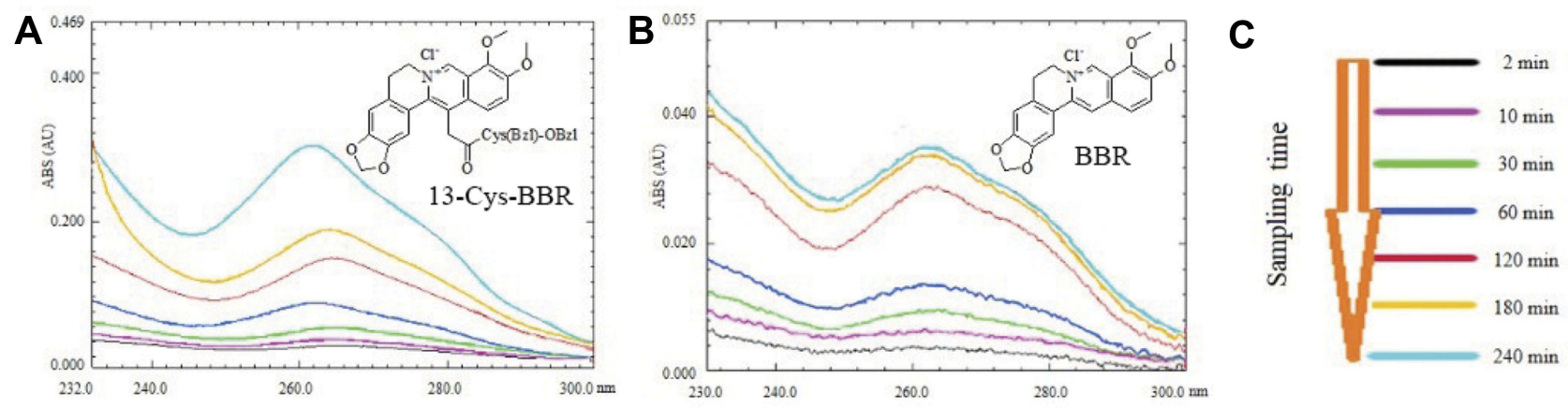

Figure 2 Correlation between UV absorbance and the capacity of BBR and I3-Cys-BBR to across the membrane: (A) time-dependent UV absorbance of the lower chamber of the transwell containing $38.3 \mu \mathrm{M}$ of I3-Cys-BBR; (B) time-dependent UV absorbance of the lower chamber of the transwell containing $72.6 \mu \mathrm{M}$ of BBR; (C) time of sampling PBS solution from the lower chamber of the transwell.

Abbreviations: BBR, berberine; 13-Cys-BBR, I3-[CH $\left.\mathrm{CH}_{2} \mathrm{CO}-\mathrm{Cys}(\mathrm{Bzl})-\mathrm{OBz} \mid\right]-$-berberine.

$(72.6 \mu \mathrm{M})$ is twice as high as that $(38.3 \mu \mathrm{M})$ of $13-\mathrm{Cys}-$ $\mathrm{BBR}$, and the time-dependent $\mathrm{UV}$ absorption of BBR is significantly lower than that of 13-Cys-BBR. This means that 13-Cys-BBR, but not BBR, effectively crosses the wall of cancer cells or mouse intestinal.

\section{3-Cys-BBR Effectively Inhibited Cancer Cell Proliferation}

The in vitro anti-proliferation activity of 13-Cys-BBR (100, 50, and $25 \mu \mathrm{M}$ ) against HCT-116, LS174T, SW620, SGC7901, Eca109, MKN28, HCT-8, and S180 cells was identified by standard MTT assay. In the assay, BBR (100, 50 , and $25 \mu \mathrm{M}$ ) and RPMI 1640 medium were used as the positive and negative controls, respectively. Figure $3 \mathrm{~A}-\mathrm{C}$ shows that at 100,50 , and $25 \mu \mathrm{M}$, the viabilities of the cancer cells treated by 13-Cys-BBR are significantly lower than those of the cancer cells treated by BBR.

The $\mathrm{IC}_{50}$ values of 13-Cys-BBR inhibiting the proliferation of the cancer cells are significantly lower than those of BBR inhibiting the proliferation of the cancer cells (Figure 4). Thus, 13-position of BBR been modified by $\mathrm{CH}_{2} \mathrm{CO}-\mathrm{Cys}(\mathrm{Bzl})-\mathrm{OBzl}$ can enhance the in vitro antitumor activity. In addition, the $\mathrm{IC}_{50}$ value suggests that S180 cells exhibit the highest sensitivity to 13-Cys-BBR. This led to the selection of S180 mice for evaluating the in vivo anti-tumor activity of 13-Cys-BBR.

\section{Increasing ROS Inside Cancer Cells Is Responsible For I3-Cys-BBR Having Higher Anti-Proliferation Activity}

To correlate the anti-proliferation activity with ROS formation, HCT-8 cells were treated by 13-Cys-BBR and BBR. For measuring ROS, the survival of HCT-8 cells needs to be more than $60 \%$. Thus, the time courses of $50 \mu \mathrm{M} 13-\mathrm{Cys}-\mathrm{BBR}, 50 \mu \mathrm{M}$ Dox, and $50 \mu \mathrm{M}$ BBR were firstly established. The time courses show that at all time points the inhibitions of 13-Cys-BBR are significantly higher than those of Dox and BBR, and the survival of HCT-8 cells treated by 13-Cys-BBR for 6 hrs is more than $60 \%$ (Figure 5). Thus, 6-hr incubation was selected for measuring ROS, and the results are shown in Figure 6. As seen, the intensity of the FITCA inside the HCT- 8 cells treated by $50 \mu \mathrm{M}$ of 13-CysBBR is 3.44-folds higher than that of the FITC-A inside the HCT-8 cells treated by $50 \mu \mathrm{M}$ of BBR. In other words, comparing to BBR the treatment of 13-Cys-BBR significantly increases HCT-8 cells to form ROS, and the relevant increase of ROS formation should be responsible for 13-Cys-BBR having higher antiproliferation activity.

Besides, the morphology of HCT-8 cells treated by PBS, 13-Cys-BBR, and BBR were visualized by fluorescence microscope and the results are shown in Figure 6. The insets of the local amplified images suggest that the size and feature of HCT- 8 cells treated by PBS are similar to those of HCT- 8 cells treated by $50 \mu \mathrm{M}$ BBR but distinctly different from those of HCT- 8 cells treated by 50 $\mu \mathrm{M}$ 13-Cys- BBR. The HCT-8 cells treated by 13-Cys$\mathrm{BBR}$ are characterized by roundness feature and decreased size.

Thus, both the FITC-A and the morphology of HCT-8 cells consistently emphasize that 13-Cys-BBR, but not $\mathrm{BBR}$, induces the accumulation of ROS inside cancer cells and thereby induces apoptosis of cancer cells. 

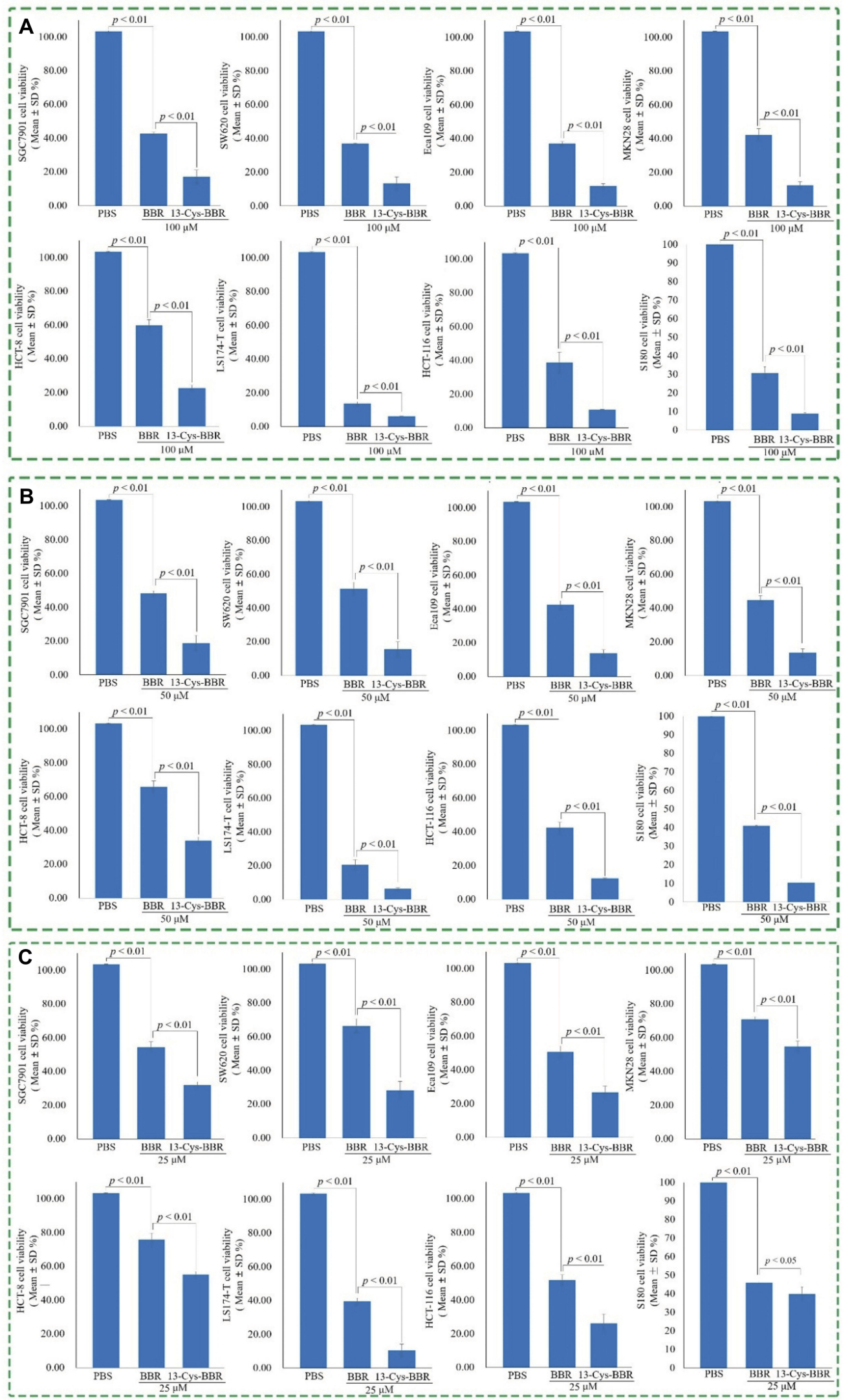

Figure 3 Concentration-dependent anti-proliferation activity in vitro: (A) activity of $100 \mu \mathrm{M}$ of I3-Cys-BBR and BBR against the cancer cell proliferation; (B) activity of 50 $\mu \mathrm{M}$ of I3-Cys-BBR and BBR against the cancer cell proliferation; (C) activity of $25 \mu \mathrm{M}$ of I3-Cys-BBR and BBR against the cancer cell proliferation; $\mathrm{n}=6$.

Abbreviations: BBR, berberine; I3-Cys-BBR, I3-[ $\left.\mathrm{CH}_{2} \mathrm{CO}-\mathrm{Cys}(\mathrm{Bz} \mid)-\mathrm{OBz} \mid\right]-$ berberine. 


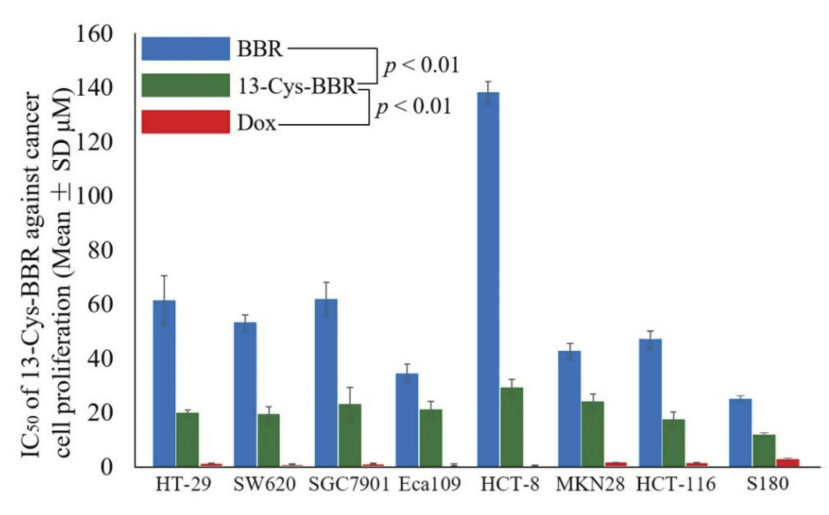

Figure $4 \mathrm{IC}_{50}$ of I3-Cys-BBR, BBR, and Dox against the cancer cell proliferation, $\mathrm{n}=6$. Abbreviations: BBR, berberine; I3-Cys-BBR, I3-[ $\left.\mathrm{CH}_{2} \mathrm{CO}-\mathrm{Cys}(\mathrm{Bzl})-\mathrm{OBz} \mid\right]-$-berberine; Dox, doxorubicin.

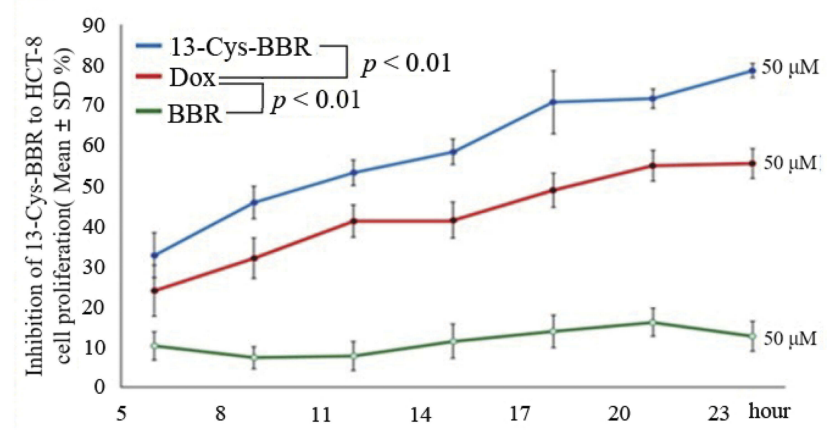

Figure 5 Time course of 13-Cys-BBR inhibiting HCT-8 cell proliferation, $n=6$. Abbreviations: BBR, berberine; Dox, doxorubicin; I3-Cys-BBR, I3-[ $\mathrm{CH}_{2} \mathrm{CO}-\mathrm{Cys}$ (OBzl)-OBzl]- berberine.

\section{3-Cys-BBR Selectively Downregulating XIAP Expression}

To show the effect of 13-Cys-BBR on the apoptosis proteins, HCT- 8 cells were treated by $25 \mu \mathrm{M}$ BBR or $25 \mu \mathrm{M}$ 13-Cys-BBR, and the level of XIAP, Cas-3, and PARP inside HCT-8 cells was quantified by Western blot. ${ }^{24}$ As seen the level of XIAP inside HCT-8 cells treated by 13-Cys-BBR is significantly lower that of XIAP inside HCT- 8 cells treated by BBR (Figure 7A), and the levels of Cap- 3 and PARP inside HCT- 8 cells treated by $13-\mathrm{Cys}-\mathrm{BBR}$ are equal to that of Cap-3 and PARP inside HCT-8 cells treated by BBR (Figure 7B and $C$ ). These results mean that 13-Cys-BBR selectively down-regulates XIAP expression, the decrease of XIAP expression is responsible for the in vitro antiproliferation activity of 13-Cys-BBR to be higher than that of BBR, and 13-Cys-BBR does not alter the antiproliferation mechanism of BBR.

\section{In Vivo I3-Cys-BBR Effectively Slowed Tumor Growth}

The in vivo anti-tumor evaluation was performed on S180 mouse model. The mice were administered with 13-Cys-BBR (oral $2 \mu \mathrm{mol} / \mathrm{kg} /$ day) or BBR (parent control, oral $2 \mu \mathrm{mol} / \mathrm{kg} /$ day) or Dox (positive control, intraperitoneal $2 \mu \mathrm{mol} / \mathrm{kg} /$ day) or $\mathrm{CMC}-\mathrm{Na}$ (oral $10 \mathrm{~mL} / \mathrm{kg} /$ day) for 11 consecutive days. The tumor weight was used to represent the activity. As seen, there is no significant difference between the tumor weights of S180 mice treated by BBR and CMC-Na, but the tumor weight of S180 mice treated by 13-CysBBR is significantly lower than those of S180 mice treated by BBR and CMC-Na (Figure 8). These demonstrate that 13-position of BBR been modified by $\mathrm{CH}_{2} \mathrm{CO}-\mathrm{Cys}(\mathrm{Bzl})-\mathrm{OBzl}$ can enhance the in vivo anti-tumor activity.

\section{3-Cys-BBR Had No Kidney And Liver Toxicity}

BBR therapy was reported to have liver and kidney toxicity. ${ }^{25}$ To estimate the injuring risk of 13-Cys-BBR to liver and kidney, the blood of S180 mice in tumor growth assay was collected. By following the specifications of the commercial kits, the serum levels of alanine aminotransferase (ALT), lactic dehydrogenase (LDH), uric acid (UA), urea, and creatinine (CREA-S) were measured. In contrast to BBR, 13-Cys-BBR does not decrease the serum ALT (Figure 9A) and LDH (Figure 9B) vitalities of the treated S180 mice. These indicate that 13-Cys-BBR has no liver toxicity. Again in contrast to BBR, 13-CysBBR does not decrease the serum UA (Figure 9C), urea (Figure 9D), and CREA-S (Figure 9E) vitalities of the treated S180 mice. These indicate that 13-Cys-BBR has no kidney toxicity.

\section{Discussion}

The discovery of novel BBR derivative having higher antitumor activity in vivo is of clinical importance. In this profile, the 13-position of BBR was modified by $\mathrm{CH}_{2} \mathrm{CO}$ -

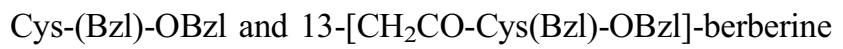
(13-Cys-BBR) was prepared with acceptable yield. The rationality of this modification was supported by a series of evidences.

The first evidence was from transwell membrane experiment. This experiment was used to simulate the wall of the cancer cells or intestinal and showed that 13- 

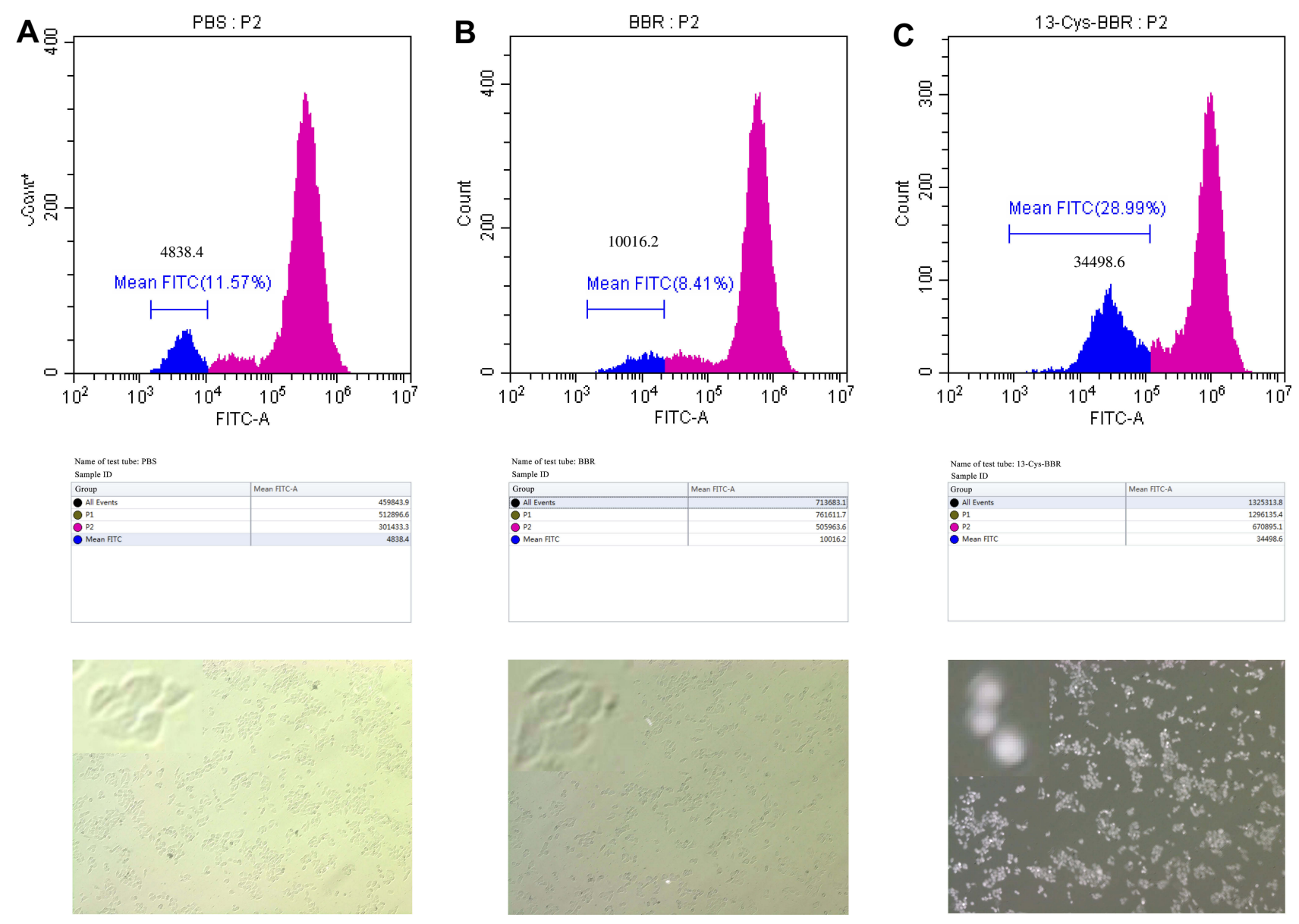

Figure 6 FITC-A of HCT-8 cells treated by PBS, BBR and I3-Cys-BBR for 6 hrs: (A) FITC-A of HCT-8 cells treated by PBS; (B) FITC-A of HCT-8 cells treated by $50 \mu$ M of BBR; (C) FITC-A of HCT-8 cells treated by $50 \mu$ M of I3-Cys-BBR.

Abbreviations: FITC-A, fluorescein isothiocyanate; BBR, berberine; I3-Cys-BBR, I3-[CH $\left.\mathrm{CH}_{2} \mathrm{CO}-\mathrm{Cys}(\mathrm{Bz} \mid)-\mathrm{OBz} \mid\right]-$ berberine.

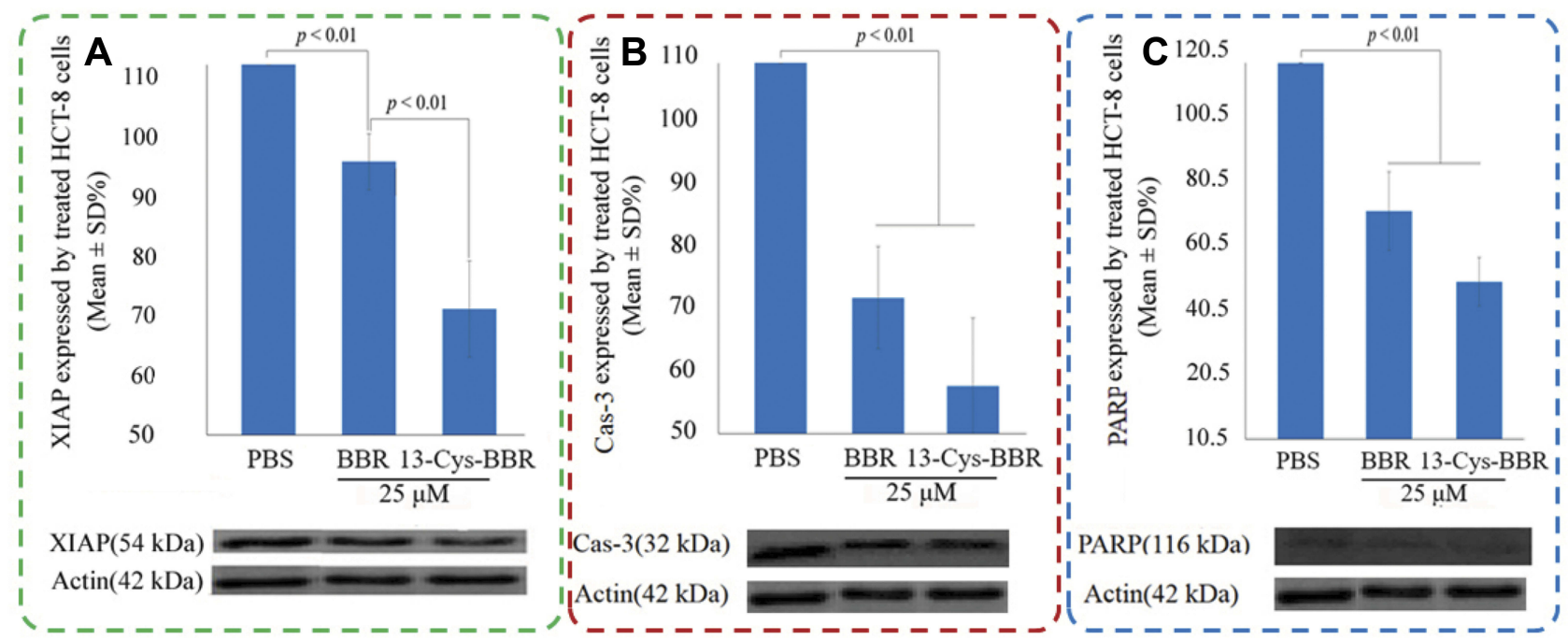

Figure 7 In vitro effect of I3-Cys-BBR and BBR on proteins inside HCT-8 cells, $n=3$; (A) XIAP level inside HCT-8 cells treated by $25 \mu M$ of BBR and $25 \mu M$ of I3-Cys-BBR; (B) Cas-3 level inside HCT-8 cells treated by $25 \mu \mathrm{M}$ of BBR and $25 \mu \mathrm{M}$ of I3-Cys-BBR; (C) PARP level inside HCT-8 cells treated by $25 \mu \mathrm{M}$ of BBR and $25 \mu \mathrm{M}$ of I3-Cys-BBR. Abbreviations: BBR, berberine; I3-Cys-BBR, I3-[CH $\left.\mathrm{CH}_{2} \mathrm{CO}-\mathrm{Cys}(\mathrm{Bzl})-\mathrm{OBz}\right]$ ]-berberine; PBS, phosphate-buffered saline; XIAP, anti-apoptosis protein; Cas-3, caspase-3; PARP, poly ADP-ribose polymerase. 


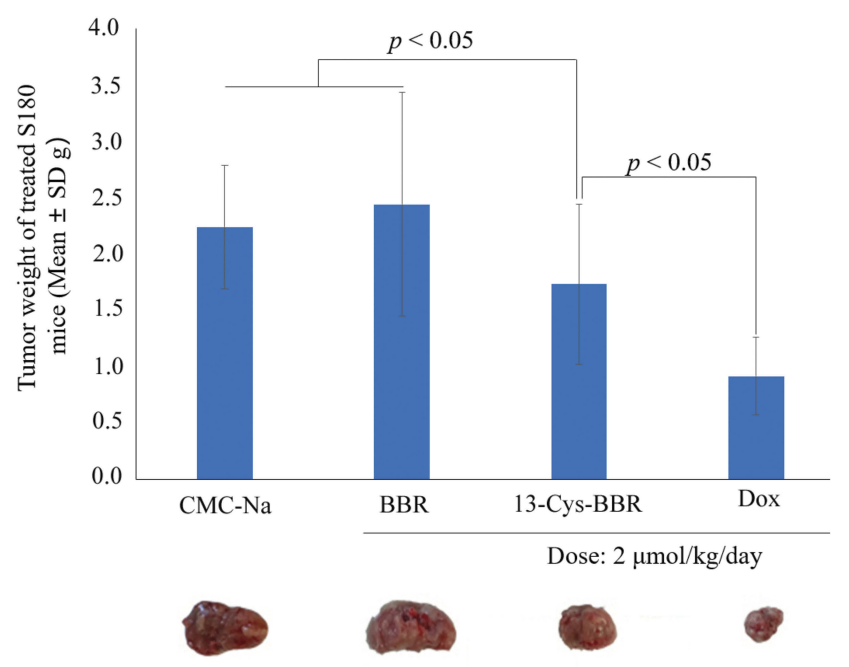

Figure 8 In vivo activities of 13-Cys-BBR, BBR, and Dox slowing tumor growth of S180 mice, $\mathrm{n}=12$.

Abbreviations: BBR, berberine; Dox, doxorubicin; 13-Cys-BBR, I3-[CH $\mathrm{CH}_{2} \mathrm{CO}-\mathrm{Cys}$ (Bzl)-OBzl]- berberine; CMC-Na, sodium carboxymethylcellulose.

Cys-BBR, but not BBR, effectively crossed the wall of the cancer cells or intestinal.

The second evidence was from the in vitro anti-proliferation assay. This assay showed that the anti-proliferation activities of 13-Cys-BBR against HCT116, LS174T, SW620, SGC7901, Eca109, MKN28, HCT-8, and S180 cells were significantly higher than those of BBR against the cells. Of the 8 cell lines, S180 cells exhibited the highest sensitivity to 13-CysBBR, and thereby S180 mouse model was selected for the in vivo anti-tumor assay.

To explore the effect of apoptosis proteins on the in vitro anti-proliferation activity, HCT-8 cells were treated by 13-Cys-BBR and BBR. Western blot was used to quantify the expressions of XIAP, Cap-3, and PARP in HCT-8 cells. As apoptosis proteins closely related to $\mathrm{BBR}$, their expressions were significantly down regulated by the treatment, but only XIAP of the HCT- 8 cells treated by BBR was significantly higher than that of the HCT- 8 cells treated by 13-Cys-BBR. These results not only demonstrated that 13-Cys-BBR had selective inhibition to XIAP expression, but also suggested that this selective inhibition should be responsible for the in vitro activity of anti-proliferation of $13-$ Cys-BBR to be significantly higher than that of BBR.

To understand the reason of 13-Cys-BBR depressing the expression of XIAP to be superior to BBR, a docking investigation was performed by following the previous operation, ${ }^{26}$ and this led 13-Cys-BBR and BBR having 133.32 and 77.33 DOCKING scores, respectively. In the interactions of 13-Cys-BBR and BBR with the active site, 8 amino acid residues and 5 amino acid residues have been involved, respectively (Figure 10). This suggests that the active site is more suitable for 13-Cys-BBR than for BBR, thereby the expression of XIAP in BBR-treated HCT-8 cells is significantly higher than that of 13-Cys-BBR-treated HCT8 cells.

To show the effect of ROS on apoptosis of cancer cells, HCT- 8 cells were treated by 13-Cys-BBR and BBR. Comparing to the flow cytometry-based intensity of FITC-A of the HCT-8 cells treated by BBR, 13-CysBBR significantly increases HCT-8 cells to form ROS. The morphology of HCT-8 cells visualized that 13-Cys-
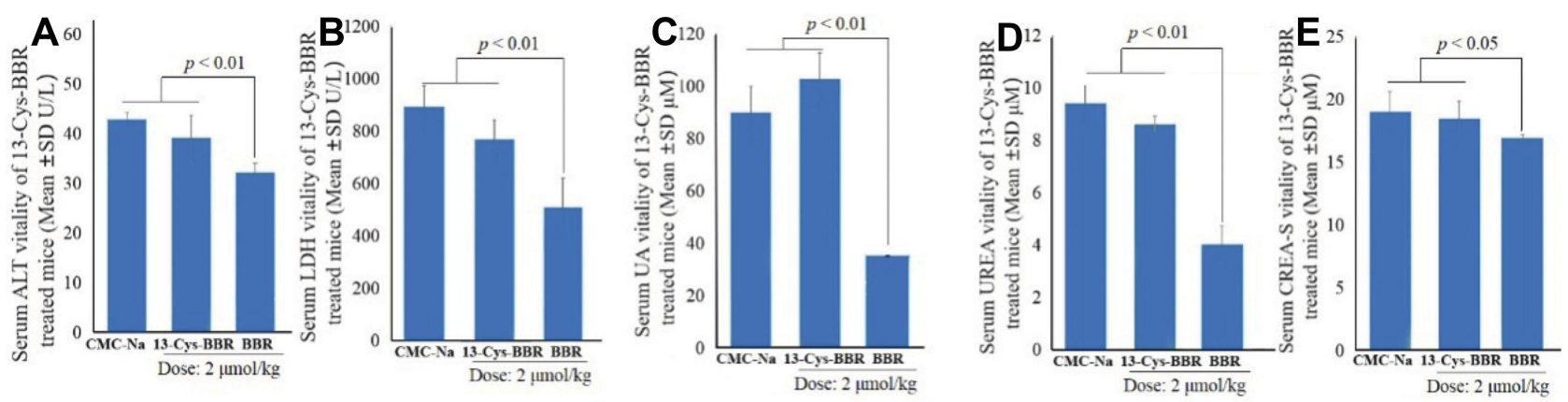

Figure 9 Effect of I3-Cys-BBR and BBR on liver and kidney: (A) serum ALT vitality of SI80 mice treated by I3-Cys-BBR and BBR; (B) serum LDH vitality of SI80 mice treated by I3-Cys-BBR and BBR; (C) serum UA vitality of SI80 mice treated by I3-Cys-BBR and BBR; (D) serum UREA vitality of SI80 mice treated by I3-Cys-BBR and BBR; (E) serum CREA-S vitality of SI 80 mice treated by I3-Cys-BBR and BBR.

Abbreviations: BBR, berberine; I3-Cys-BBR, I3-[CH $\mathrm{CH}_{2} \mathrm{CO}-\mathrm{Cys}(\mathrm{Bz})$-OBzl]-berberine; CMC-Na, sodium carboxymethylcellulose; ALT, alanine aminotransferase; LDH, lactic dehydrogenase; UA, uric acid; CREA-S, creatinine. 


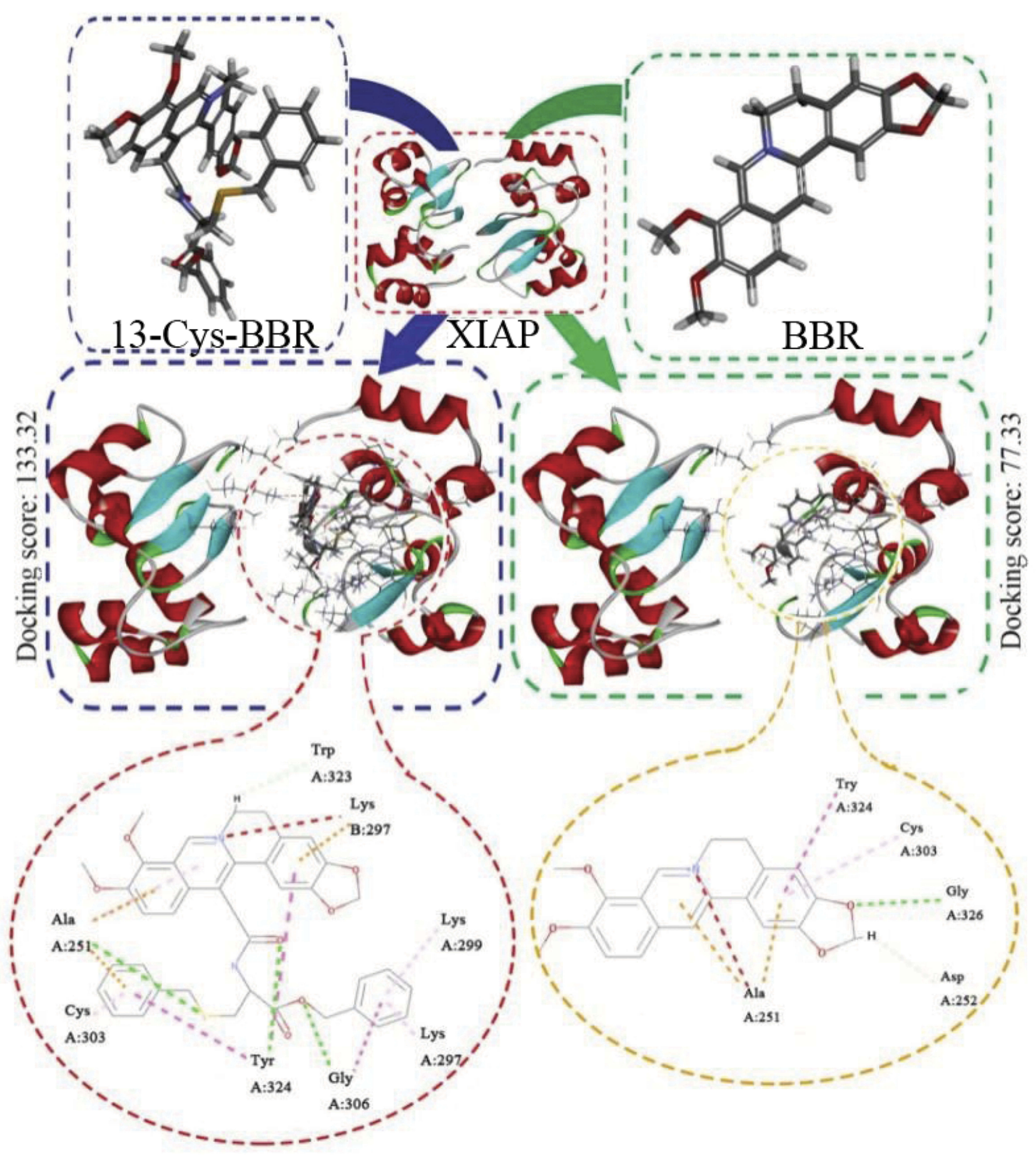

Figure 10 Docking feature of $13-C y s-B B R$ and $B B R$ in the active site of XIAP.

Abbreviations: $B B R$, berberine; I3-Cys-BBR, I3-[CH $\left.\mathrm{CH}_{2} \mathrm{CO}-\mathrm{Cys}(\mathrm{Bz} \mid)-\mathrm{OBz} \mid\right]-$ berberine; $\mathrm{XIAP}$, anti-apoptosis proteins.

BBR, but not BBR, increased ROS and induced apoptosis of HCT-8 cells .

The third evidence was from the in vivo anti-tumor assay. This assay showed that at a dose of $2 \mu \mathrm{mol} / \mathrm{kg} / \mathrm{day}$ 13-Cys-BBR, but not BBR, effectively slowed the tumor growth of S180 mice. As mentioned earlier, in the Western blot experiment, BBR effectively depressed HCT-8 cells to express XIAP, Cap-3, and PARP. This means that in vitro and in vivo BBR has distinct behavior and suggests that BBR effectively depressing HCT-8 cells to express XIAP, Cap-3, and PARP only contributes to in vitro antiproliferation activity, but not to in vivo anti-tumor activity. 


\section{Conclusion}

In conclusion, as a novel derivative 13-Cys-BBR effectively overcome the poor bioavailability of BBR in vitro and in vivo, does not change the action mechanism of BBR; the treatment of 11 consecutive days BBR, but not 13-Cys-BBR, injures the liver and the kidney of S180 mice; 13-Cys-BBR should be a promising candidate for pre-clinical investigation.

\section{Acknowledgment}

The authors thank the Special Project of China (2018ZX097201003), NSFC (81673303 and 81572779), BNSF (7172028) and KM201810025010 for financial support.

\section{Disclosure}

The authors report no conflicts of interest in this work.

\section{References}

1. Wang N, Feng Y, Tang HY, et al. Berberine and coptidis rhizoma as potential anticancer agents: recent updates and future perspectives. J Ethnopharmacol. 2015. doi:10.1016/j.jep.2015.10.028.

2. Yang SS, Yu CB, Xu WN, et al. Berberine attenuates sodium palmitate-induced lipid accumulation, oxidative stress and apoptosis in grass carp(Ctenopharyngodonidella)hepatocyte in vitro. Fish Shellfish Immunol. 2019. doi:10.1016/j.fsi.2019.02.055

3. Ren K, Zhang W, Han X, et al. Synergistic anti-cancer effects of galangin and berberinethroughapoptosis induction and proliferation inhibition in oesophageal carcinoma cells. Biomed Pharmacother. 2016. doi:10.1016/j.biopha.2016.10.111

4. Hu S, Chen CW, Wang SW, et al. Inhibitory effect of berberine on interleukin-2 secretion from PHA-treatedlymphocyticJurkat cells. Int Immunopharmacol. 2019. doi:10.1016/j.intimp.2018.11.020.

5. Chang Y-P, Huang CC, Ueng Y-F, et al. Differential inhibition of CYP1-catalyzed regioselective hydroxylation of estradiol by berberine and its oxidative metabolites. Drug Metab Pharmacokinet. 2015. doi:10.1016/j.dmpk.2015.08.006.

6. Naveen CR, Gaikwad S, Agrawal-Rajput. R. Authenticity in relationships: predicting caregiving and attachment in adult romantic relationships. J Couns Psychol. 2016. doi:10.1037/cou0000128.

7. Ahmed T, Nabavi SM, Stein DJ, et al. 12-week double-blind randomized multicenter study of efficacy and safety of agomelatine (25-50 mg/day) versus escitalopram (10-20 mg/day) in out-patients with severe generalized anxiety disorder. Pharmacol Rep. 2018. doi:10.1016/j.euroneuro.2018.05.006.

8. Kumar A, Dhull DK, Chopra K, et al. Current knowledge and pharmacological profile of berberine: an update. Eur J Pharmacol. 2015. doi:10.1016/j.ejphar.2015.05.068.

9. Yu Y, Wen X, Hao G, et al. Berberine induces GLP-1 secretion through activation of bitter taste receptor pathways. Biochem Pharmacol. 2015. doi:10.1016/j.bcp.2015.07.012

10. Lang S, Steinritz D, Popp T, et al. Anti-apoptotic and moderate anti-inflammatory effects of berberine in sulfur mustard exposed keratinocytes. Toxicol Lett. 2018. doi:10.1016/j.toxlet.2017.09.004.
11. Luganini A, Loregian A, Mercorelli B, et al. The isoquinoline alkaloid berberine inhibits human cytomegalovirus replication by interfering with the viral Immediate Early-2 (IE2) protein transactivating activity. Antiviral Res. 2019. doi:10.1016/j.antiviral.2019.02.006.

12. Hashemi-Niasari F, Fallah S, Razmi M, et al. Synergy of theophylline reduces necrotic effect of berberine, induces cell cycle arrest and PARP, HMGB1, Bcl-2 family mediated apoptosis in MDAMB- 231 breast cancer cells. Biomed Pharmacother. 2018. doi:10.1016/j. biopha.2018.07.019.

13. Zhang H, Shang W, Shan Y, et al. Berberine suppresses LPS-induced inflammation through modulating Sirt1/NF- $\mathrm{B}$ signaling pathway in RAW264.7 cells. Int Immunopharmacol. 2017. doi:10.1016/j. intimp.2017.08.032.

14. Wang Y, Zhang S. Berberine suppresses growth and metastasis of endometrial cancer cells viamiR-101/COX-2. Biomed Pharmacother. 2018. doi:10.1016/j.biopha.2018.04.161.

15. Tsang CM, Feng Y, Cheung KC, et al. Berberine suppresses Id-1 expression and inhibits the growth and development of lung metastases in hepatocellular carcinoma. Biochim Biophys Acta. 2015;1852:541-551. doi:10.1016/j.bbadis.2014.12.004.

16. Li Y-H, Bian Z-X, Xiao HT, et al. Berberine ameliorates chronic relapsing dextran sulfate sodium-induced colitis in C57BL/6 mice by suppressing Th17 responses. Pharmacol Res. 2016. doi:10.1016/j. phrs.2016.02.010.

17. Li J-W, Guo Y, Shang S-C, et al. A safer hypoglycemic agent for type 2 diabetes-berberine organic acid salt. J Funct Foods. 2017; 38:399-408. doi:10.1016/j.jff.2017.09.031.

18. Wong S, Chin K-Y, Ima-Nirwana S. Berberine and musculoskeletal disorders: the therapeutic potential and underlying molecular mechanisms. Phytomedicine. 2019:10. doi:10.1016/j.phymed.2019.15 2892

19. Popiołek I, Szczubiałka K, Niziolek A, et al. Cellular delivery and enhanced anticancer activity of berberine complexed with a cationic derivative of $\gamma$-cyclodextrin. Bioorg Med Chem. 2019. doi:10.1016/j. bmc.2019.02.042.

20. Hao M, Li W, Liu L, et al. The design and synthesis of a novel compound of berberine and baicalein that inhibits the efficacy of lipid accumulation in 3T3-L1 adipocytes. Bioorg Med Chem. 2017. doi:10.1016/j.bmc.2017.08.013.

21. Li Y-H, Bian Z-X, Zhang $M$, et al. Pre-clinical toxicity of a combination of berberine and 5-aminosalicylic acid in mice. Food Chem Toxicol. 2016. doi:10.1016/j.fct.2016.08.031.

22. Gupta L, Gupta U, Sharma AK, et al. Dendrimer encapsulated and conjugated delivery of berberine: a novel approach mitigating toxicity and improving in vivo pharmacokinetics. Int J Pharm. 2017. doi:10.1016/j.ijpharm.2017.04.073.

23. Liu G-A, Li G-C, Tian Y-L, et al. Berberine induces apoptosis in HepG-2 initiated by reactive oxygen species. J Northwest Normal Univ (Nat Sci). 2017. doi:10.16783/j.cnki.nwnuz.2017.03.017.

24. Gan T, Peng S, Wang Y, et al. 5-(Bis(3-(2-hydroxyethyl)-1H-indol -2-yl)methyl)-2-hydroxybenzoic acid (BHI MHA): showing a strategy of designing drug to block lung metastasis of tumors. Drug Des Devel Ther. 2016. doi:10.2147/DDDT.S93570.

25. Kim S, Lee SY, Cho H-J. Berberine and zinc oxide-based nanoparticles for the chemophotothermaltherapy of lung adenocarcinoma. Biochem Biophys Res Commun. 2018. doi:10.1016/j.bbrc.2018.05. 063.

26. Chen H, Peng S, Zhao M, et al. Design and development of ICCA ICCA as a dual inhibitor of GPII b/III a and P-selectin receptors. Drug Des Devel Ther. 2018. doi:10.2147/DDDT.S169238.

27. Wang J, Yang F, Yang T, et al. The synthesis and antistaphylococcal activity of 9, 13-disubstitutedberberine derivatives. Eur J Med Chem. 2017. doi:10.1016/j.ejmech.2017.01.012. 


\section{Publish your work in this journal}

OncoTargets and Therapy is an international, peer-reviewed, open access journal focusing on the pathological basis of all cancers, potential targets for therapy and treatment protocols employed to improve the management of cancer patients. The journal also focuses on the impact of management programs and new therapeutic

Submit your manuscript here: https://www.dovepress.com/oncotargets-and-therapy-journal agents and protocols on patient perspectives such as quality of life, adherence and satisfaction. The manuscript management system is completely online and includes a very quick and fair peer-review system, which is all easy to use. Visit http://www.dovepress.com/ testimonials.php to read real quotes from published authors. 